\title{
Excellent Solid Lubrication of Electrodeposited Nickel-Multiwalled Carbon Nanotube Composite Films
}

\author{
Susumu Arai ${ }^{\mathrm{a}, *}$, Akihiro Fujimori $^{\mathrm{b}}$, Masami Murai ${ }^{\mathrm{b}}$, Morinobu Endo ${ }^{\mathrm{c}}$ \\ a Department of Chemistry and Material Engineering, Faculty of Engineering, \\ Shinshu University, Nagano 380-8553, Japan \\ b Watch Operation Division, Seiko Epson Corporation, Shiojiri, Nagano \\ 399-0796, Japan \\ ${ }^{\mathrm{c}}$ Department of Electrical and Electronic Engineering, Faculty of Engineering, \\ Shinshu University, Nagano 380-8553, Japan
}

*Corresponding author: Susumu Arai

Tel: +81-26-269-5413 fax: +81-26-269-5432

E-mail address: araisun@shinshu-u.ac.jp

\section{E-mail addresses for co-authors}

Akihiro Fujimori: fujimori.akihiro@exc.epson.co.jp

Masami Murai: murai.masami@exc.epson.co.jp

Morinobu Endo: endo@endomoribu.shinshu-u.ac.jp 


\section{Abstract}

Nickel-multiwalled carbon nanotube (MWCNT) composite films were fabricated by an electrodeposition technique, and their frictional properties were investigated by ball-on-plate type friction testing using an $\mathrm{Al}_{2} \mathrm{O}_{3}$ ball as a counter surface without lubricant. Ni-MWCNT composite films showed superior frictional properties compared to nickel films. The friction coefficient of Ni-MWCNT composite films decreased with increasing MWCNT content. The Ni-0.5mass\% MWCNT composite film showed the minimum friction coefficient value of 0.13 .

Keywords: Carbon nanotube; Nickel; Electrodeposition; Solid lubrication; Wear; Coatings 


\section{Introduction}

Carbon nanotubes (CNTs) [1,2] have excellent mechanical characteristics, such as high tensile strength and high elastic modulus, and also have high thermal and electrical conductivity. Therefore, research into the practical applications of CNTs, especially CNT composites, has been actively pursued. CNTs also have superior friction properties, and thus, tribological properties of CNT composites such as resin-CNTs [3-7], ceramic-CNTs [8-10], and metal-CNTs [11-16] have been investigated extensively for practical applications. Metal-CNT composites coatings[12-16] are particularly promising as friction abrasion resistance technology for a wide range of applications.

Most studies on the tribological properties of metal-CNT composite coatings have focused on the electroless nickel plating technique [12-15]. There have been very few reports on the tribological properties of electrodeposited metal-CNT composite films. Moreover, most experiments on electroless Ni-CNT composite films have been conducted under lubricated conditions.

Chen et al. reported the tribological properties of electroless Ni-CNT composite deposits under dry conditions using a steel ball as a counter surface [14]. They showed that the wear resistance of electroless Ni-CNT composite deposits was excellent but the friction coefficients were relatively large.

The present authors and others have reported the fabrication of metal-CNT composite films, such as Cu-CNT $[17,18]$ and Ni-CNT $[19,20]$, by 
electrodeposition and the excellent thermal conductivity obtained for electrodeposited Ni-CNT composite films [19].

In the present study, we demonstrate the excellent solid lubrication of Ni-CNT composite films prepared by electrodeposition.

\section{Experimental}

The CNTs used were commercially available (Showa Denko Co. Ltd.) vapor-grown multiwalled carbon nanotubes (MWCNTs), obtained via catalyst-assisted CVD [21], and heat-treated at $2800^{\circ} \mathrm{C}$ in argon for $30 \mathrm{~min}$. The MWCNTs were typically $100-200 \mathrm{~nm}$ in diameter and $20 \mu \mathrm{m}$ in length. A Ni-plating bath $\left(1 \mathrm{M} \mathrm{NiSO}_{4} \cdot 6 \mathrm{H}_{2} \mathrm{O}+0.2 \mathrm{M} \mathrm{NiCl}_{2} \cdot 6 \mathrm{H}_{2} \mathrm{O}+0.5 \mathrm{M} \mathrm{H}_{3} \mathrm{BO}_{3}+0.01\right.$ M saccharin sodium dihydrate $+2.5 \times 10^{-3} \mathrm{M}$ 2-butyne-1,4-diol), called "bright Watts Bath”, was used as the basic plating bath. MWCNTs did not disperse uniformly in the basic bath. A homogeneous dispersion of MWCNTs was achieved by the addition of polyacrylic acid (mean molecular weight: 5000; PA5000) to the basic bath as a dispersing agent with stirrer agitation and ultrasonication. The composition of the composite plating bath used was $1 \mathrm{M}$ $\mathrm{NiSO}_{4} \cdot 6 \mathrm{H}_{2} \mathrm{O}+0.2 \mathrm{M} \mathrm{NiCl}_{2} \cdot 6 \mathrm{H}_{2} \mathrm{O}+0.5 \mathrm{M} \mathrm{H}_{3} \mathrm{BO}_{3}+0.01 \mathrm{M}$ saccharin sodium dihydrate $+2.5 \times 10^{-3}$ M 2-butyne-1,4-diol $+2 \times 10^{-5} \mathrm{M}$ PA5000 $+x \mathrm{~g} \mathrm{dm}^{-3}$ MWCNTs. Plating was performed at $25^{\circ} \mathrm{C}$ with aeration under galvanostatic conditions. A commercially available electrolytic cell (Model I, Yamamoto-Ms Co. Ltd.) with internal dimensions of $65 \times 65 \times 95 \mathrm{~mm}$ was employed for electrodeposition. The volume of the plating bath was $250 \mathrm{~cm}^{3}$. A pure copper plate with an exposed area of $10 \mathrm{~cm}^{2}(3 \times 3.3 \mathrm{~mm})$ was used as a 
substrate for characterization of the micro-texture of Ni-MWCNT composite films. A SK-4 steel plate with buffing $(\mathrm{Hv}=700, \mathrm{Ra}=5 \mathrm{~nm})$ with an exposed surface area of $4 \mathrm{~cm}^{2}(2 \times 2 \mathrm{~cm})$ was used as a substrate for the measurement of tribological properties. A pure nickel plate was used as the anode. The MWCNT content of the composite films was weighed directly. ${ }^{19}$ The film thickness was about $20 \mu \mathrm{m}$. The Ni-MWCNT composite films were examined using field-emission scanning electron microscopy (FE-SEM; JEOL JSM-7000F). An exclusive sample preparation equipment (cross-section polisher; JEOL SM-09010) was used to prepare cross-sectional samples for observation.

The tribological properties were measured using a ball-on-plate type reciprocating friction abrasion test machine (Shinko Engineering Co. Ltd. 758046). An alumina ball $(4.763 \mathrm{~mm}$ in diameter, $\mathrm{Hv}=1500)$ was used as the counter-surface. The reciprocating friction stroke was $10 \mathrm{~mm}$, and the tests were conducted under a normal load of $1 \mathrm{~N}$. The average sliding speed was 40 $\mathrm{mm} \mathrm{s}^{-1}\left(2\right.$ cycle s$\left.^{-1}\right)$ and the number of cycles was 2600 . All measurements were performed under ambient conditions without any lubricants. During the tests, the friction coefficient was measured continuously using a load cell.

\section{Results and discussion}

Figure 1 shows surface and cross-sectional SEM images of Ni-MWCNT composite films. The MWCNT content of the composite film was about 0.5 mass\%. The MWCNTs were distributed homogeneously across the surface of the film, i.e., the surface was homogeneously covered with MWCNTs (Fig. 1a). 


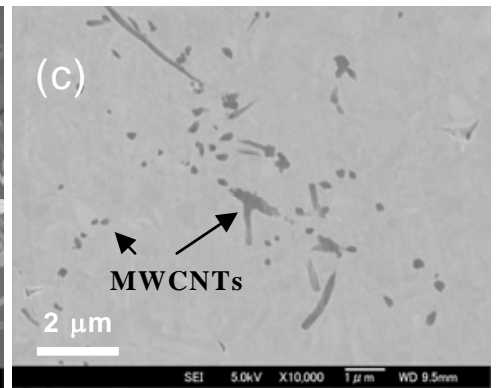

Figure 1

The MWCNTs are tightly incorporated within the deposited nickel (Fig. 1b). There are a few nickel deposits on the MWCNTs, but the MWCNT surfaces were largely free of deposited nickel (Fig. 1b). The dark areas in Fig. 1c are the cross-sections of MWCNTs, and the bright area is the nickel matrix. Thus, the MWCNTs were incorporated into the nickel matrix and distributed homogeneously throughout the matrix.

Figure 2 shows the friction behavior of nickel and Ni-MWCNT composite films. In the case of the nickel film, the friction coefficient increased rapidly at an early stage, and then reached a steady value of 0.33 . But the fluctuation of the friction coefficient was very large. For Ni-MWCNT composite films, the friction coefficients clearly decreased compared to that of the nickel film and the friction coefficients decreased with increasing MWCNT content of the composite film. The friction coefficient of Ni-0.1 mass\% MWCNT composite film initially increased rapidly, and then increased gradually, finally settling at 0.28 . The fluctuation was relatively small. The friction coefficient of the Ni-0.5mass\% MWCNT composite film increased rapidly at the very beginning, and then decreased gradually, finally reaching a steady value of 0.13 . The fluctuation was very small. Thus, the Ni-MWCNT composite films clearly showed solid lubrication. 


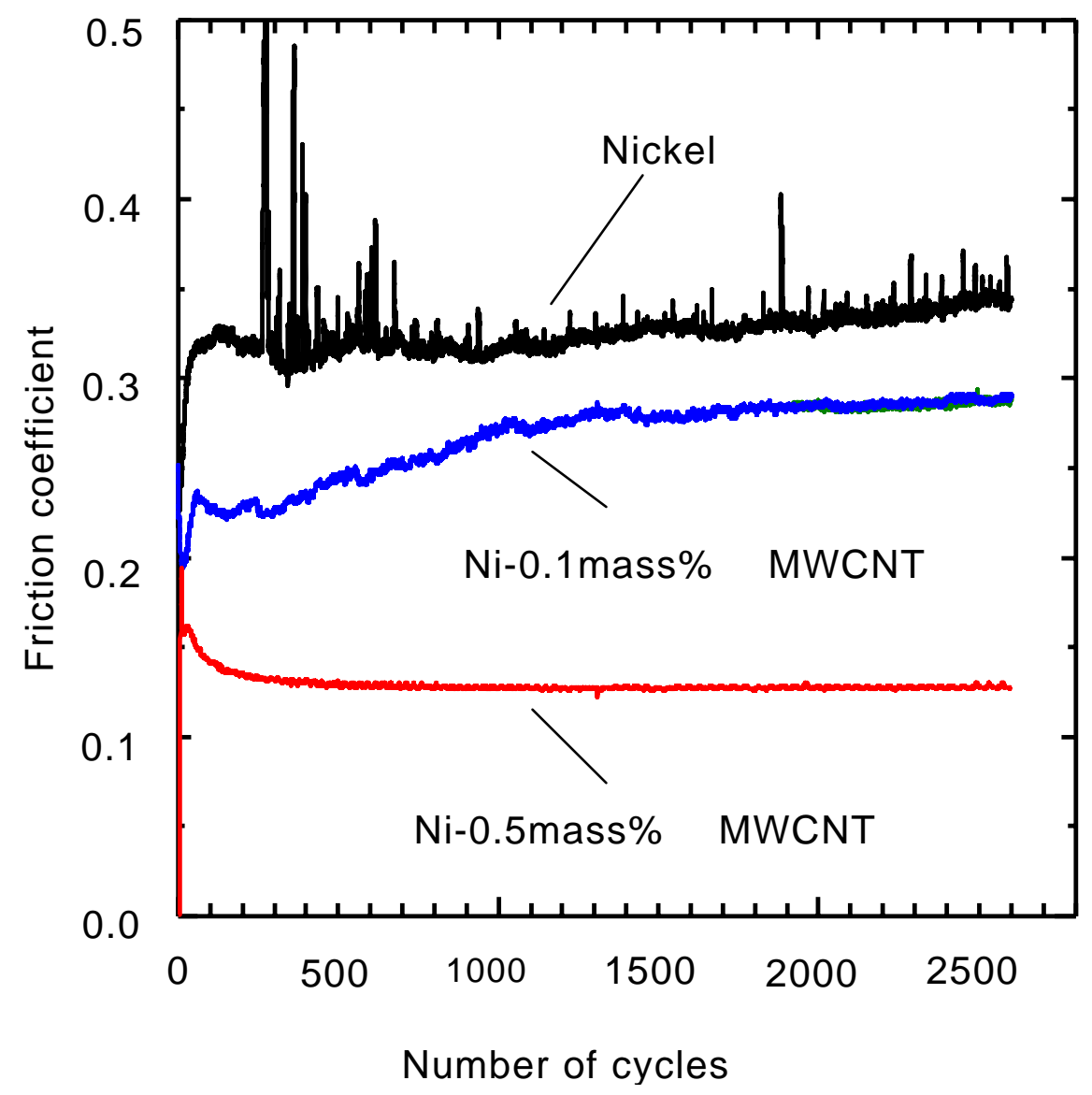

Figure 2

The overwhelming argument for the reduction of friction in CNT composite materials has been based on the hypothesis of the intrinsic self-lubricity of CNTs $[3,12]$ at the tribological surface. Many have reported actual measurements of the friction coefficient of MWCNTs themselves [22-28]. Dickrell et al. have measured the friction coefficients of vertically and transversely aligned MWCNTs to be 0.795 and 0.090 , respectively, using a borosilicate glass pin as a counter surface under ambient conditions [23]. The friction coefficient of the Ni-0.5mass\% MWCNT composite film was comparable to that of the transversely aligned MWCNTs. Thus, it can be concluded that MWCNTs at the tribological surface, especially the side walls 
of MWCNTs, acted effectively as a solid lubricant, resulting in a decrease in the friction coefficient. It has been reported that the friction coefficient of electroless Ni-CNT composite coatings under dry conditions varied from 0.75 to 1.2 according to the applied normal load [14]. The friction coefficient of 0.13 obtained in the present study is extremely low compared to the above values.

Figure 3 shows SEM micrographs of worn surfaces of nickel and Ni-0.5mass\% MWCNT composite films after wear testing. The worn area of the nickel film was relatively large compared to that of the $\mathrm{Ni}-0.5 \mathrm{mass} \%$ MWCNT composite film (Figs. 3a and 3c). The entire surface of the worn area of the nickel film was damaged (Fig. 3b), while the surface of the

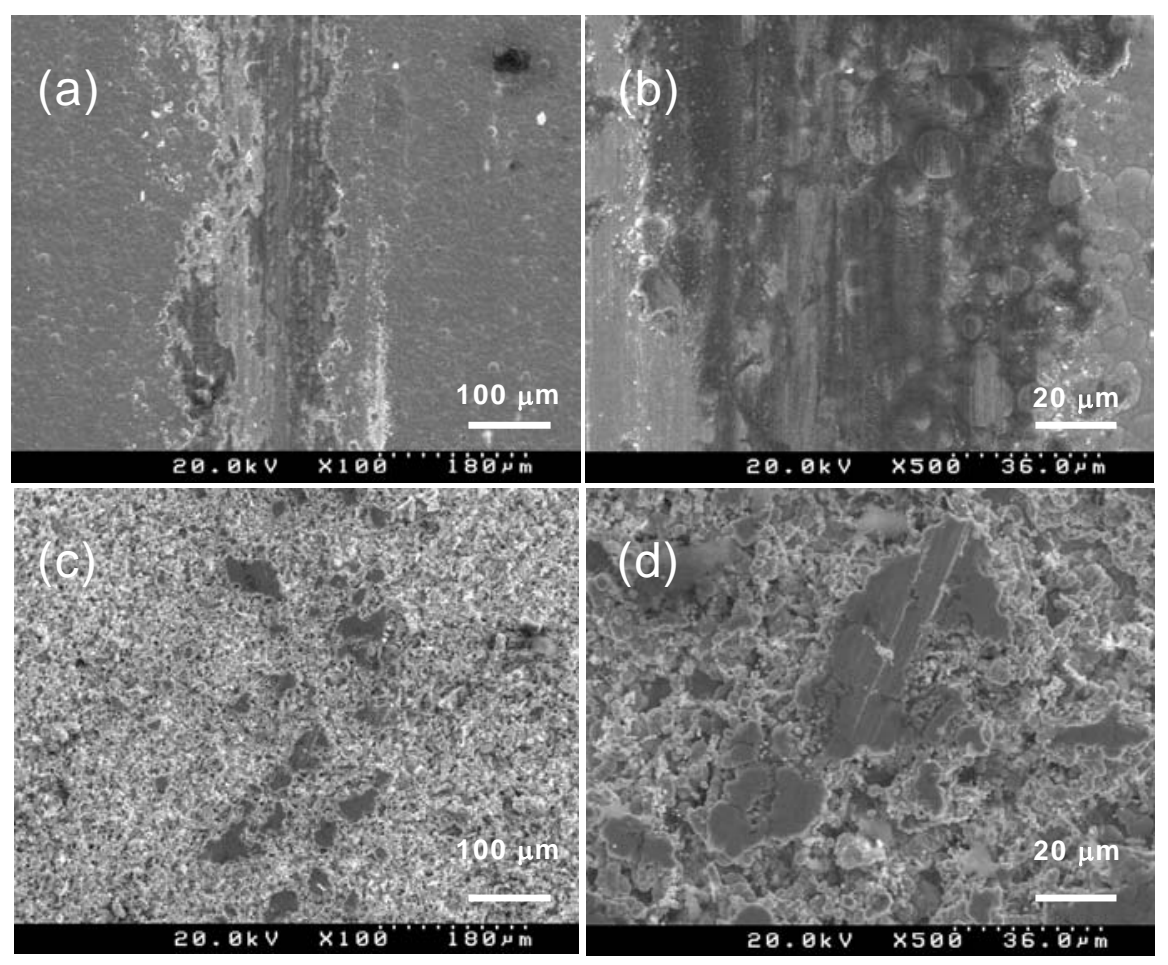

Figure 3 
Ni-0.5mass\% MWCNT composite film was only partly damaged. This means that the Ni-0.5mass\% MWCNT composite film was damaged only on the surface of its convex sections. These results are not consistent with the superior friction coefficient of the Ni-MWCNT composite film.

Figure 4 schematizes the superior solid lubrication of the Ni-MWCNT composite film. The MWCNTs are arranged randomly on the surface of Ni-MWCNT composite film before the wear test (Fig. 4a). In this state, some of the MWCNTs may still be arranged vertically with respect to the alumina ball and the friction coefficient may be high. Once the wear test starts, the alumina ball scratches the Ni-MWCNT composite film, and the surface, especially the nickel matrix, is gradually deformed plastically. Consequently, the MWCNTs are gradually arranged transversely, resulting in a lower friction coefficient (Fig. 4b). Indeed, the friction coefficient was relatively high in the early stages, decreasing gradually with increasing number of cycles (Fig. 2).

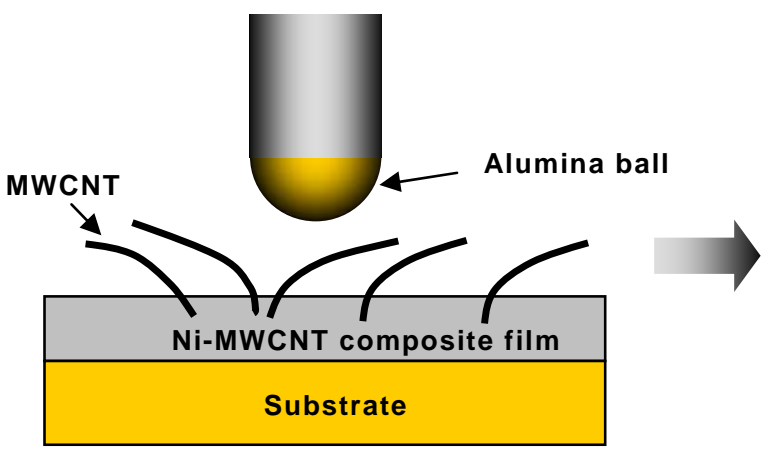

(a)

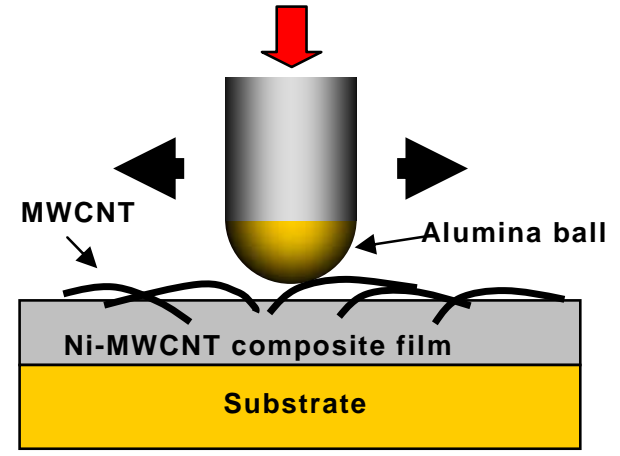

(b)

Figure 4 


\section{Conclusion}

We have fabricated Ni-MWCNT composite films by an electrodeposition technique, and investigated their tribological properties. The Ni-MWCNT composite films showed lower friction coefficients under dry conditions, i.e., superior solid lubrication, decreasing to as low as 0.13 . We believe that the Ni-MWCNT composite films can apply to the aerospace, automobile and other industries as frictional components. 


\section{References}

[1] A. Oberlin, M. Endo, T. Koyama, J. Cryst. Growth 32 (1976) 335.

[2] S. Iijima, Nature 354 (1991) 56.

[3] W. X. Chen, F. Li, G. Han, J. B. Xia, L. Y. Wang, J. P. Tu, Z. D. Xu, Tribol. Lett. 15 (2003) 275.

[4] Yeong-Seok Zoo, Jeong-Wook An, Dong-Phil Lim, Dae-Soon Lim, Tribol. Lett. 16 (2004) 305.

[5] H. Cai, F. Yan, Q. Xue, Mater. Sci. Eng. Struct. Mater. Properties Microstruct. Process. 364 (2004) 94.

[6] A. Tanaka, K. Umeda, M. Yudasaka, M. Suzuki, T. Ohana, M. Yumura, S. Iijima, Tribol. Lett. 19 (2005) 135.

[7] O. Jacobs, W. Xu, B. Schadel, W. Wu, Tribol. Lett. 23 (2006) 65.

[8] E. Flahaut, A. Peigney, C. Laurent, C. Marliere, F. Chastel, A. Rousset, Acta Mater. 48 (2000) 3803.

[9] R. W. Siegel, S. K. Chang, B. J. Ash, J. Stone, P. M. Ajayan, R. W. Doremus, L. S. Schadler, Scripta. Mater. 44 (2001) 2061.

[10] G. D. Zhan, J. D. Kuntz, J. L. Wan, A. K. Mukherjee, Nat. Mater. 2 (2003) 38 .

[11] J. P. Tu, Y. Z. Yang, L. Y. Wang, X. C. Ma, X. B. Zhang, Tribol. Lett. $10(2001) 225$. 
[12] W. X. Chen, J. P. Tu, L. Y. Wang, H. Y. Gan, Z. D. Xu, X. B. Zhang, Carbon 41 (2003) 215.

[13] W. X. Chen, J. P. Tu, Z. D. Xu, W. L. Chen, X. B. Zhang, D. H. Cheng, Mater. Lett. 57 (2003) 1256.

[14] X. H. Chen, C. S. Chen, H. N. Xiao, H. B. Liu, L. P. Zhou, S. L. Li, G. Zhang, Tribol. Int. 39 (2006) 22.

[15] Z. H. Li, X. Q. Wang, M. Wang, F. F. Wang, H. L. Ge, Tribol. Int. 39 (2006) 953.

[16] J. Tan, T. Yu, B. Xu, Q. Yao, Tribol. Lett. 21 (2006) 107.

[17] S. Arai, M. Endo, Electrochem. Solid-State Lett. 7 (2004) C25.

[18] S. Arai, M. Endo, Electrochem. Commun. 7 (2005) 19.

[19] S. Arai, M. Endo, T. Sato, A. Koide, Electrochem. Solid-State Lett. 9 (2006) C131.

[20] S. Arai, T. Saito, M. Endo, J. Electrochem. Soc. 154 (2007) D530.

[21] M. Endo, CHEMTECH 18 (1988) 568.

[22] A. Hirata, N. Yoshioka, Tribol. Int. 37 (2004) 893.

[23] P. L. Dickrell, S. B. Sinnott, D. W. Hahn, N. R. Raravikar, L. S. Schadler, P. M. Ajayan, W. G. Sawyer, Tribol. Lett. 18 (2005) 59.

[24] V. Turq, N. Ohmae, J. M. Martin, J. Fontaine, H. Kinoshita, J. L. Loubet, Tribol. Lett. 19 (2005) 23. 
[25] J. J. Hu, S. H. Jo, Z. F. Ren, A. A. Voevodin, J. S. Zabinski, Tribol. Lett. 19 (2005) 119.

[26] K. Miyoshi, K. W. Street Jr., R. L. van der Wal, Rodney Andrews, Ali Sayir, Tribol. Lett. 19 (2005) 119.

[27] P. L. Dickrell, S. K. Pal, G. R. Baurne, C. Muratore, A. A. Voevodin, P. M. Ajayan, L. S. Schadler, W. G. Sawyer, Tribol. Lett. 24 (2006) 85.

[28] N. Ohmae, Tribol. Int. 39 (2006) 1497. 
Figure Captions

Figure 1. Surface and cross-sectional SEM images of a Ni-0.5mass\% MWCNT composite film: (a) surface SEM image under (a) low magnification and (b) high magnification, and (c) cross-sectional SEM image.

Figure 2. Variation in friction coefficient as a function of number of cycles for the nickel film and the Ni-MWCNT composite films. The nickel film was formed using the basic plating bath.

Figure 3. SEM images of worn surfaces: (a) nickel film, (b) the film in (a) under higher magnification, (c) Ni-0.5mass\% MWCNT composite film, and (d) the film in (c) under higher magnification.

Figure 4. A schematic illustration of the superior solid lubrication of a Ni-MWCNT composite film: (a) before the wear test and (b) during the wear test. 